\title{
Learning Community or Community of Practice: Preliminary Findings of a Transfer of Learning Study
}

\author{
John P Egan \\ Learning Technology Unit, Faculty of Medical and Health \\ Sciences, The University of Auckland, Auckland, New Zealand
}

\section{j.egan@auckland.ac.nz}

\begin{abstract}
This exploratory study examines the learning community and community of practice aspects of an online applications course. Transfer of learning (Caffarella, 2002) was significant for nearly all study participants. The learning community purposefully fomented as part of the course design was a significantly positive and effective element of course design and delivery, supported by instructor presence. However, the community of practice aspect during the course (Lave and Wenger, 1991), whilst strong, was not as evident after the course ended. This paper represents a preliminary analysis of the findings from the quantitative (questionnaire) portion of a larger, mixed methods scholarship of teaching and learning (SOTL) study.
\end{abstract}

Keywords: elearning, transfer of learning, community of practice, learning community, mixed methods, scholarship of teaching and learning.

\section{Introduction}

To a significant extent, students in post-graduate professional programs expect to be able to apply what they learn in ways that will improve their practice. However, for various reasons, many professionals - particularly educational professionals - find this transition challenging. In professional education, undergraduate studies tend to be more focused on competency-based skill acquisition, whilst post-graduate studies emphasize more sophisticated, critical analyses of the profession, including practice but also policy, culture and context, or continuing professional education. One might argue that all curriculum development (sometimes called program planning in adult education scholarship) that includes a competency-based pedagogies are inherently focused on bringing what is learned in the educational context into practice. There is an emerging consensus that this migration of skills - what Caffarella describes as the transfer of learning (2002) - in fact requires specific and purposeful curriculum design for transfer to happen consistently, effectively and smoothly.

Then, to what extent can the purposeful integration of specific learning activities to foment trans-

Material published as part of this publication, either on-line or in print, is copyrighted by the Informing Science Institute. Permission to make digital or paper copy of part or all of these works for personal or classroom use is granted without fee provided that the copies are not made or distributed for profit or commercial advantage AND that copies 1) bear this notice in full and 2) give the full citation on the first page. It is permissible to abstract these works so long as credit is given. To copy in all other cases or to republish or to post on a server or to redistribute to lists requires specific permission and payment of a fee. Contact Publisher@InformingScience.org to request redistribution permission. fer of learning impact learners' ability to apply new knowledges in their practice? Are some sorts of learning activities better suited to this goal? Are there other aspects of a professional educational experience, such as how a course is managed and delivered-inclusive of, but in a much broader sense than, merely the specific learning activities - that can impact transfer of learning? 
This paper reports preliminary findings about the transfer of learning experience related to an elective, wholly online, post-graduate applications course in educational technology. Specific data related to the course culture, framed around the notions of learning communities (Anderson, 2008) and communities of practice (Lave \& Wenger, 1991) are contextualized through an articulation of the design process behind these aspects of one such course, ETEC565A, in a wholly online post-graduate educational technology program: the University of British Columbia's Master of Educational Technology (MET) program.

\section{Transfer of Learning}

There is an extensive literature related to transfer of learning in adult education scholarship. Caffarella, whose work in program planning has given transfer of learning arguably the greatest currency, defines transfer of learning as "the effective application by program participants of what they learned as a result of attending an education or training program" (2002, p. 204). She notes that transfer of learning has "often been thought of in behavioural terms - that is, what is to be transferred can be clearly specified in terms of observable changes in knowledge, skills and attitudes." (2002, p. 205). Brookfield (2005) offers a somewhat different definition of transfer of learning as "the process by which learners apply, in settings outside of an...educational setting, the skills and knowledge they have learned within that setting" (p. 627). There are no substantive differences between Caffarella's and Brookfields's definitions.

Sork notes that "devising transfer of learning plans" as important in the program planning (or curriculum) process (2011, p. 162), and credits Caffarella with bringing the concept of transfer of learning to the fore, since "most (curriculum) models are silent on this important aspect of planning, or just assume that this will be taken care of when designing instruction" (2011, p. 162). Among numerous transfer of learning techniques identified by Caffarella (p. 217), individualized learning plans, mentoring, (e)portfolios, networking, and reflective practice all feature prominently in the course design for ETEC565A.

\section{Learning Community, Community of Practice}

Early in the development process we endeavoured to design a course with a learning community (Anderson, 2008) at its core, ideally one that formed the basis of an community of practice (Lave \& Wenger, 1991) during the course (and program), and subsequent to course and program completion. Subsequently, as the course instructor I have tried to align my practice with these principles.

While many focus on Lave and Wenger's notion of "legitimate peripheral participation (p. 29) when discussing communities of practice, Lave and Wenger's other, ostensibly broader points, are sometimes lost: peripheral participation is merely one phase or period of community of practice membership. For skilled practitioners, moving beyond the rudiments of nascent practice requires a shift towards the centre (rather than remaining on the periphery) of a community of practice. In fact, Lave and Wenger advise:

"Rather than learning by replicating the performances of others or by acquiring knowledge transmitted in instruction, we suggest that learning occurs through centripetal participation in the learning curriculum of the ambient community. Because the place of knowledge is within a community of practice, questions of learning must be addressed within the development cycles of that community, a recommendation which creates a diagnostic tool for distinguishing among communities of practice." (p. 100)

We have tried to create a course where legitimate peripheral participation accelerates through centripetal participation. 
While a community of practice can ostensibly be bounded by a specific context or educational experience (such as ETEC565A), within this specific experience the fomentation of a learning community has value and currency. Anderson's characterization of a learning community as a space where members "both support and challenge each other, leading to effective and relevant knowledge construction" (2008, p. 39) also informed our design work-and my pedagogy. We tried, therefore, to create a course where both during the course a vibrant learning community facilitates and enables each student's learning, whilst subsequent to the course's (and the program's) completion a community of practice was available for course participants as they sought to apply and refine what they had learned. It merits noting that these concepts - community of practice and learning community - are ones that are infused across multiple courses in the MET program. Thus, in terms of face validity those recruited for this study should have a clear understanding of these terms as informed by the literature cited.

Across the MET program's student community there is a wealth of knowledges and skills. Resultingly, collegial support and advice are positioned firmly at the centre of several courses offered in the program. ETEC565A has been designed in a way that purposefully leverages this, making collaborative learning - formal and informal - as integral to success in the course. In instructional design terms, our course design sought to provide learning activities that foment, support, and leverage community and its concomitant interactions. Endeavouring to garner a richer understand these centripetal, ambient, and cyclical aspects of each cohort of ETEC565A's learning community and community of practice dynamics were therefore a focus of this study.

\section{About the MET Program, About the Course}

UBC's Master of Educational Technology (MET) program, a wholly online magistral learning technologies program (http://met.ubc.ca/) has been in operation since 2002, and is one of the first wholly online degree programs offered at a major, research-intensive, Canadian university. Since its inception over 300 students have completed the program, studying on either a full-time or parttime basis. Program students (currently or previously enrolled) include persons based in Canada, the United States, Mexico, Asia, Europe, the Caribbean, Latin America and Oceania. Since its launch the MET's emphasis has been on informed, critical analysis of the implementation of technology in a variety of teaching and learning contexts.

In addition to core courses in research methods, instructional design, educational technology foundations, and learning theory, students choose from a range of elective courses focused around subject matters such as math and science or liberal arts education, developing learning technology ventures, and issues related to indigeneity and learning technologies. This course is also an elective, though its subscription levels are near to the required courses.

Learning Technologies: Selection, Design and Application (ETEC565A) was launched in May 2009. To date over 300 students have completed the course: demand for the course, in fact, is higher than our capacity to offer it. The course uses a range of theoretical frameworks to assist purposefully evaluate, select and deploy various learning technologies whilst giving students hands-on experience with a diverse spectrum of learning technologies and platforms.

As we began to develop ETEC565A, one key question informed our work: what sorts of core competencies would we expect someone who had completed a post-graduate qualification in educational technology to possess? For ETEC565A the core competencies we identified were:

- A solid understanding of key literatures related to tool selection, learning theory and learning technology deployment best practices

- Familiarity with professional standards related to educational technology

- The ability to create a learning management system (LMS) course site with a customized 
(“cracked") graphical user interface (GUI)

- Creation of a sophisticated online assessment object (quiz or exam), using a diverse range of question types, affordances and assessment strategies, as part of an overall course assessment strategy

- Development and delivery of a high calibre, pedagogically purposeful digital story

- Use of weblogs and/or wikis for site design, as learning objects, and as an e-portfolio platform

- Mindfulness of issues related to intellectual property, confidentiality, and data ownership

- Design for accessibility

- An ongoing practice of self-reflection informed by relevant literatures

The process by which these were developed was not linear. Some of these competencies emerged early on in the design process; others surfaced as we created both formative and summative assessments. The final list is, in fact, roughly 50 per cent as long as the original. And the list was significantly refined significantly after each of the first two cycles of course offerings, with continued refinements thereafter. The development of ETEC565A has been, in other words, a somewhat untidy process.

\section{Study Design}

This mixed methods, exploratory study rigorously examine aspects of student experiences both during ETEC565A and subsequent to having completed the course. The research questions for this study are:

- What are the perspectives of students who have completed ETEC565A with respect to the course and its subsequent value?

- What sorts of impact has ETEC565A had on their practice as educators, if any?

The study has two phases. The quantitative phase consists of a self-administered online questionnaire; the qualitative phase consists of key informant interviews of a sub-sample of respondents to the questionnaire. Data collection for phase one commenced in May 152012 and will conclude in February 2013. Interviews for phase two commenced in August 2012 and will continue through March 2013. This paper reflects preliminary analyses of phase one data findings received as of September 2012.

The questionnaire included the following aspects of respondents' experience:

1. Professional experience

2. Program experience

3. Active learning course component

4. Elearning toolkit wiki course component

5. Formative assessment course component

6. Summatively assessment course component

7. Learning communities and communities of practice

8. Impact on practice (capstone questions)

9. Demographic information for classification purposes

The questionnaire was developed based on a review of the current literature, the documentation from the design team for ETEC565A and in collaboration with colleagues knowledgeable about 
learning technologies, transfer of learning and scholarship of teaching and learning methodology. Five item Likert-scale questions were often used (example: Strongly Disagree - Disagree - Not Sure - Agree - Strongly Agree), which were in some instances collapsed down to three item scales (example: Disagree - Not Sure - Agree) for statistical analyses.

Questionnaire invitations were sent via the university's student information service beginning in May 2012. Reminders were sent mid-May and early June. Out of 269 students who were invited to participate in the study, three had email addresses that bounced back, making an adjusted population of 266. A total of 86 completed the survey, for a response rate of 32 per cent. The survey was delivered via VoVici, a locally hosted-based online survey development tool, since local privacy laws in British Columbia Canada preclude using server-based technologies based outside of Canada. Statistical analyses were done using VoVici and SPSS 20 for Mac OS X. University Behavioural Research Ethics Board approval for the study was granted (UBC BREB Number H12-00986).

Note: many of the alumni of ETEC565A (and the MET program, by extension) work as public school teachers at the primary, intermediate or secondary level. Others, however, work in different contexts as educational professionals, not always as teachers, instructors or facilitators. Thus the study design and language used in the data collection process needed to be inclusive of this breadth of professional educational practice to be captured: hence the use of "educational professionals" rather than "educators" or "teachers" throughout this paper.

\section{The Participants}

Mean and median ages for respondents were both 42 years at the time of survey completion. Almost two-thirds of respondents were female; fully three quarters had completed a bachelor of education program. Educational attainment levels were skewed towards having completed one or more magistral degrees (seventy-three per cent), most often the MET program itself: three per cent had completed a doctorate. Most respondents - 68 per cent-worked full-time (defined as 35 hours per week or more), viewed themselves as "early adopters" of new technologies (84\%) and "learning technologies leaders" (83\%). A somewhat smaller number considered themselves "learning technologies innovators" (67\%).

Respondents worked in a range of contexts. Almost half worked in primary or secondary education, though post-secondary, adult and community, and higher education were also represented. Of the one quarter who selected "other", the roles described included educational technologist, instructional designer, administrator, coordinator, project manager, principal and consultant. Eighty-seven per cent had been an educational professional for five or more years: only one per cent were in the first year of their education career. Half had worked five or more years in their current role; six per cent were in theirs for less than one year.

Of their (not mutually exclusive) reasons for enrolling in the MET program, 80 per cent cited "an interest in learning technologies", which was the most common response. Conversely, only 10 per cent cited the absence of any face-to-face post-graduate program available near their home community as a reason. At the time of survey completion, 44 per cent had completed the MET program, most in 2011. Another 24 per cent had completed 7 to 9 (out of 10) courses; most of the remaining respondents were less than halfway through the program.

\section{Findings}

Overall, ETEC565A provided a valuable and effective learning experience for most who complete it: the learning community and community of practice components were of specific value. Ninety-two per cent of respondent found the learning community design employed in ETEC565A 
significantly, very or highly relevant, with 67 per cent finding it very or highly relevant. Table One outlines these results:

Table 1: Relevance of Learning Community Aspect of Course

\begin{tabular}{|l|l|}
\hline Learning community aspect was: & Per cent \\
\hline Highly relevant & 42 \\
\hline Very relevant & 24 \\
\hline Significantly relevant & 25 \\
\hline Marginally or not relevant & 8 \\
\hline Prefer not to answer & 1 \\
\hline
\end{tabular}

In terms of the community of practice aspect of the course, most agreed there was a community of practice in ETEC565A whilst the course was delivered, as described in Table Two:

Table 2: There was a Community of Practice

\begin{tabular}{|l|l|}
\hline There was a community of practice: & Per cent \\
\hline Strongly agree & 44 \\
\hline Agree & 43 \\
\hline Not sure & 8 \\
\hline Disagree & 1 \\
\hline Strongly disagree & 3 \\
\hline Prefer not to answer & 1 \\
\hline
\end{tabular}

Further, when asked whether "the course design laid the foundation for the community of practice", most students $(86 \%)$ agreed or strongly agreed. Concomitantly, while this aspect of the course design was effective, it was only effective because of the ways in which the students engaged with the community. In fact, 72 per cent of respondents agreed or strongly agreed "the students initiated and maintained the community of practice". Most (76\%) also agreed or strongly agreed "the instructor was a key member of the community of practice." During the course, therefore, we were successful in creating and supporting a community of practice because of purposeful design, student engagement and instructor engagement.

Once the course ended, however, it was a different story. Only 15 per cent agreed or strongly agreed "the ETEC565A community of practice has continued after the course ended." A more positive outcome relates to the MET program overall: fully 46 per cent of respondents felt a program-level MET community of practice existed. A clearer understanding of why this is the case, including how participants differentiate between a course-level versus program-level communities of practice, are a key aspect of the ongoing qualitative phase of the study.

\section{Specific Course Elements}

Any impacts of specific elements of the course design were also examined in the questionnaire, in order to better understand their merits for inculcating a learning community. To set the tone early in the course, two different icebreaker activities were required. First, students introduced themselves in a traditional text-based LMS discussion forum. To validate their participation and encourage interactivity, the instructor acknowledged each introduction with a specific follow-up 
question, to demonstrate presence. Sixty-one per cent of respondents viewed this activity as either "very" or "of great" value (only 10 per cent as "limited value").

As well, students were required to post a digital audio "hello" message in the course Wimba Voiceboard audio discussion forum. We elected to integrate a digital audio introduction activity for several reasons. First, using multimedia added elements of tone and voice sometimes difficult to create in text only spaces. Second, we would be leveraging virtual classroom technology later in the course and ensuring everyone had their computers configured for Wimba Voiceboard allowed us to onboard and troubleshoot with students early one. Finally, anticipating that for many students this would be a first experience with digital media, the relative speed with which one can get Wimba Voiceboard up and running made it a reasonable extension of users' technological skill sets. Although not as positively received as the more traditional introductory discussion forum, 28 per cent saw the Voiceboard activity as "very" or "of great" value; another 32 per cent saw it having "significant" value. Conversely 36 per cent saw it as having "limited" or "no" value.

Although ETEC565A students create individual e-portfolios (using the university's WordPress installation (http://blogs.ubc.ca/), we try to leverage really simple syndication (RSS) feeds to encourage student-student (Anderson, 2008) interactions outside of the LMS environment. Students were required to post the feed link for their e-portfolios once configured; after all links were posted the instructor creates and uploades an outline processor markup language (OPML) file that aggregates all the e-portfolio feeds for a cohort, along with instructions on how to deploy the OMPL file with a range of RSS feed aggregator applications. A substantial (if not overwhelming) number of respondents viewed this use of RSS feeds as being of significant $(22 \%)$, very $(17 \%)$ or great $(8 \%)$ value. About as many, however, felt it was of no $(11 \%)$ or limited $(38 \%)$ value.

Aside from multiple, activity-specific LMS discussion forums, the course LMS site has a separate discussion section for those seeking support with specific tools or technologies. The instructor purposefully holds back from answering questions in this space, in order to allow for studentstudent interactions to develop. Unless someone posted erroneous information (as a question or in response to others' queries), students were left to provide this support to one another. Most respondents found a lot of value in these forums: great $(27 \%)$, very $(32 \%)$ or significant $(25 \%)$ value. Merely nine per cent found them of either limited or no value. This approach appeared to work well.

In terms of instructor presence, only nine percent agreed that the instructor's overall presence in the course "was minimal": fully 83 per cent disagreed or strongly disagreed with this claim. Similarly, 87 per cent agreed or strongly agreed that instructor presence enhanced the discussion forums.

\section{Conclusions}

To a significant extent transfer of learning occurs subsequent to completion of ETEC565A for many student. In most respects, respondents agree that the learning community aspect of the course was an important element of the course. What less unclear from the survey data is the extent to which the learning community element contributed to transfer of learning. This is one of the key themes for the qualitative phase of the study.

Similarly, whilst a significant number of respondents have found a course- or program-specific community of practice persists afterwards, many do not. To what extent this is indicative of the course design, or is perhaps representative of the challenges education professionals face in maintaining membership in any community of practice is unclear. These questions too are being explored in the subsequent key informant interviews being conducted. 
One more cohort of students will complete ETEC565A in December 2012 and have been invited to participate in this SOTL study. Any interviews for this last cohort should be completed by April 2013, at which point analyses of the qualitative data, as well as inferential analyses of the quantitative survey data, will be conducted.

\section{References}

Anderson, T. (2008). Towards a theory of online learning. In: T. Anderson \& F. Elloumi (Eds.), Theory and practice of online learning. Edmonton AB: Athabasca University. Accessed online 3 March 2009 http://www.aupress.ca/books/120146/ebook/02_Anderson_2008_Anderson-Online_Learning.pdf

Brookfield, S. (2005). Transfer of learning. In L. English (Ed.), International encyclopedia of adult education (pp. 627-630). New York: Palgrave MacMillan.

Caffarella, R. S. (2002). Planning programs for adult learners: A practical guide for educators, trainers, and staff developers (2nd ed.). San Francisco: Jossey-Bass.

Lave, J., \& Wenger, E. (1991). Situated learning: Legitimate peripheral participation. New York: Cambridge University Press.

Sork, T. J. (2011). Planning and delivering programs. In C. E. Kasworm, A. D. Rose \& J. M. Ross-Gordon (Eds.) Handbook of adult and continuing education (pp. 57-166). Los Angeles: SAGE Publishing.

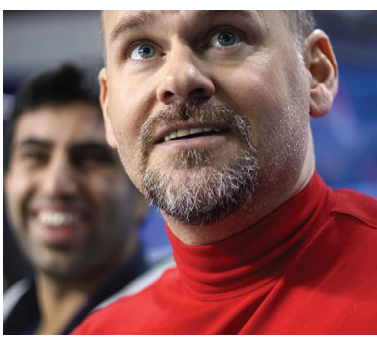

\section{Biography}

John P Egan, PhD is Director of the Learning Technology Unit in the University of Auckland's Faculty of Medical and Health Sciences. He has provided leadership in adult and higher education in New Zealand and internationally, a great deal of which has focused on elearning. He has managed educational, research, and other projects in both the public and private sectors, and has published extensively in scholarly journals, academic presses and mainstream media. 